\title{
Promoting Women in Physics and Astronomy Through a Public Lecture Series at UW-La Crosse
}

\begin{abstract}
S. R. Lesher
Physics Department, University of Wisconsin - La Crosse, La Crosse, WI ${ }^{1}$

Abstract

Undergraduate women in the Physics Department at UW- La Crosse form a small percentage of majors and are spread out across years and among sub-programs. In addition, they may encounter few women scientist during their undergraduate career. As a result, they can feel isolated and uncertain about careers in their chosen fields. A women speaker was brought to UW - La Crosse to serve as a role model for undergraduate women in the physics program and to expose them to career opportunities in a space-related field. The speaker gave an interdisciplinary science seminar, a physics specific lecture, and met with students over lunch in small group discussion. Student feedback was very positive, and the visit increased the exposure to the different careers women, and all students, could have in science.
\end{abstract}

\section{Introduction - Context and Background}

The University of Wisconsin-La Crosse (UW-L) is one of the most thriving undergraduate physics programs in the nation with approximately 165 physics majors and thirteen full-time faculty members. The department offers a B.S. in physics with optional emphases in astronomy, computational physics or optics. In addition, students can pursue a B.S. in physics with a concentration in either biomedical physics or business. Finally, the department also offers a highly successful physics-engineering dual degree program in collaboration with four engineering colleges in Wisconsin and Minnesota. In 2003, the National Task Force on Undergraduate Physics Education selected the UW-L Physics Department as one of the most successful in the country and included it as one of their case studies ${ }^{2}$. Later in 2003 an article in the September 2003 issue of Physics Today described the UW-L program as among the few "great" physics programs in the nation [1]. Each year, the American Institute of Physics (AIP) Statistical Research Center publishes a list of Bachelors-only departments averaging 10 or more physics bachelors degrees per year in its Physics Undergraduate Enrollments and Degrees data in the nation. This year, the UWL Physics Department was ranked $2^{\text {nd }}$ in the nation, averaging 28 graduates per year for classes in 2010 to 2012 [2]. In 2012, the AIP Division of Education visited our department in their study to learn and propagate effective practices for the preparation of physics undergraduates for Science, Technology, Engineering and Mathematics (STEM) career pathways. Our Department was chosen because of our strong record of preparing students with a bachelor degree in physics and placing them into STEM fields. Most recently, the UW-L Physics Department was awarded the 2013 American Physics Society (APS) “Award for Improving Undergraduate Physics Education" along with MIT, Colorado School of Mines and Kettering University. Many physics students have received national recognition for their achievements, and have pursued advanced physics and engineering degrees.

\footnotetext{
1 This work was supported by the Wisconsin Space Grant Consortium and the UW-L Physics Department.

2 Their report is available at <http://www.aapt.org/Projects/ntfup.cfm>.
} 
Despite these strengths, the physics program has difficulty attracting women and underrepresented minorities. Of the approximately 8,500 university undergraduate students at UW-L, 45\% of them are registered in the College of Science and Health where the Physics program is housed. Over half of the students in the College of Science and Health are women. However, only about $15 \%$ of the physics majors are women. The national average is about $20 \%$. Similarly, only about $2 \%$ of the physics majors are from underrepresented minorities, against a national average of about $8 \%$ [3].

\section{Project}

In an attempt to increase the number of women physics majors and to highlight the careers of successful women in the field, the Physics Department has instituted a Public Lecture Series in Physics featuring women and other underrepresented minorities in Physics. We applied for a WSGC Special Initiatives award to support this program. The Public Lecture Series in Physics has three objectives:

(1) to increase the recognition of women physicists in the local community,

(2) to recognize the scientific accomplishments and contributions of women physicists, and

(3) to have these women serve as role models for the undergraduate population at UW-L.

The speaker was M. Darby Dyer, Ph.D., Kennedy-Schelkunoff Professor of Astronomy at Mount Holyoke College. The event lasted two days and included many activities for students. On Wednesday she gave a physics seminar titled "Calibrating ChemCam: Analytical Chemistry at Arm's Length". Thursday Dr. Dyer met with undergraduate students for lunch in an informal, intimate setting. That evening she gave a public lecture entitled "A year in the Life of Curiosity on Mars: New Discoveries from the Red Planet" appropriate for all students and the general public.

\section{Assessment}

Seminar: Dr. Dyer gave two talks during her time in the Physics Department. The Physics Seminar was during the regular Physics Seminar time-slot, with an audience composed primarily of Physics majors, but including students and faculty from other departments and at the university. Approximately 100 students, faculty, and general public were in attendance at this seminar. Approximately 200 students, faculty, and members of the general public attended the Public Lecture. The students and faculty members were part of a diverse group from various departments throughout the university. The surveys indicated both the seminar and lecture were informative to the students in attendance and are shown in the following Figure 1. The survey was taken by both physics and non-physics students (about 50/50). The respondents gave high ratings to the Seminar and Lecture on several variables: how much they enjoyed it, how appropriate the level was for the audience, how supportive they are of the opportunity for students provided by the program, and whether or not they learned something new from the experience.

Lunch: The speaker also met with interested over lunch to discuss issues facing women in physics and astronomy. This allowed the students to ask question in an informal, intimate setting. Dr. Dyer gave the "inside info" on what it is like to be a woman in the field. About 45 students attended this event. Approximately $67 \%$ of those surveyed enjoyed the informal setting, interacting 
with the speaker, and believed the interaction gave them insight into women in physics and astronomy issues.

Figure 1: Average ratings of speaker from Physics Seminar $(n=44)$ and the Public Lecture $(n=36), 1=$ strongly disagree, 5 = strongly agree with the following statements: (1) I enjoyed attending the talk. (2) The talk was given at an appropriate level for the audience. (3) I'm glad UW-L allows these opportunities to students and the community. (4) I learned something new.

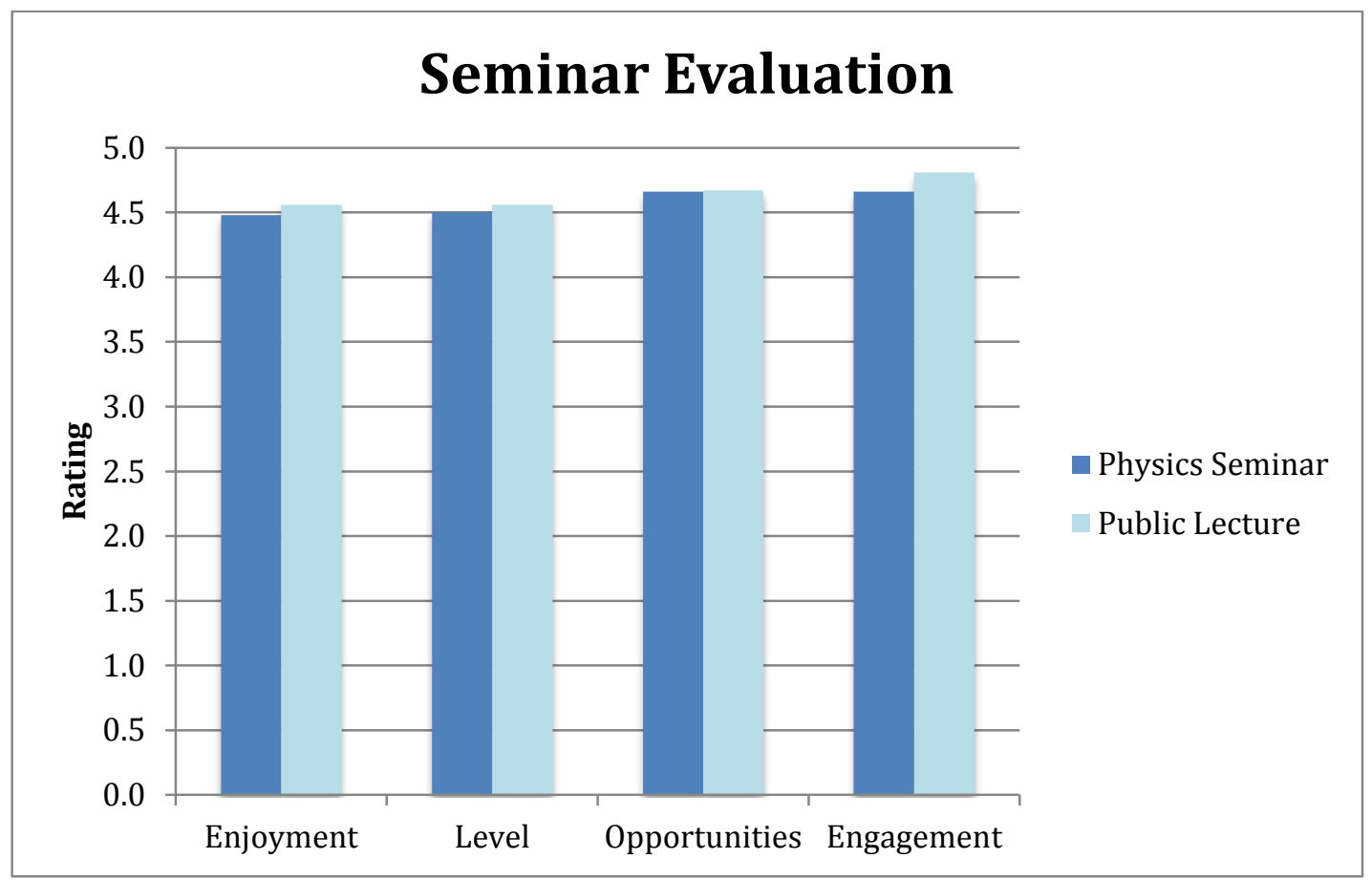

\section{Conclusion}

This program directly benefited the women of UW-L Physics Department by:

- giving them the opportunity to hear and interact with a top scientist

- giving them the opportunity to talk in small groups with the speaker about being a woman in science

Finally, $82 \%$ of those surveyed agreed that the Physics Department should make this Lecture Series an annual event featuring a woman speaker. The survey indicate that the students appreciate the opportunity to meet more women scientists, hear about their research, and discuss issues relating to a career in science. It has helped these young women envision both the challenges and rewards of becoming the next generation of experts in Physics / Engineering fields, including the possibility of pursuing space- or aerospace-related science, design, or technology. Taylor Bailey, a junior physics major, sums it up, "Dr. Darby Dyar's visit to UW-L last spring gave me a chance to not only learn about the incredible advances in the field of spectroscopy applied to the most recent Mars rover expedition, but also talk with her about being a woman in science and the struggles she and other women face everyday. This scientist is working for an organization I can only dream about getting a chance to apply to and her interesting background in chemistry, 
geology, and physics shows me that as long as I continue to be passionate about what I'm doing, I will find work that is fulfilling and enjoyable and that women in the sciences can, in fact, do it all."

\section{References}

[1] Hilborn \& Howes, Physics Today, September (2009) pg. 38.

[2] American Institute of Physics. Web. 2014 <http://www.aip.org/statistics/trends/highlite/edphysund/table4e.htm>.

[3] "APS Bridge Program." American Physical Society. Web. 09 Jan. 2013. <https://www.uwgb.edu/WSGC/k12/requirements/si.aspx>. 